\title{
Delayed facial palsy after head injury
}

\author{
K. PUVANENDRAN, M. VITHARANA, AND P. K. WONG \\ From the University Department of Medicine, and the Department of Otorhinolaryngology, \\ Singapore General Hospital, Singapore
}

SUMMARY Where facial palsy follows head injury after many days, the mechanism is not clear, and there has been no detailed study on this condition. In this prospective study, an attempt is made to estimate this complication of head injury, and to study its pathogenesis, natural history, prognosis, and sequelae which differ markedly from Bell's palsy. It has a much worse prognosis and so surgical decompression should be considered early in this condition.

The facial nerve is the motor cranial nerve which is most commonly affected in closed head injuries (Turner, 1943). In facial palsy which immediately follows a head injury, the mechanism is obvious, but it is not clear when the facial palsy follows the head injury after many days (Potter and Braakman, 1976). Traumatic facial palsy has received much attention but few authors distinguish between immediate and delayed palsy.

Turner (1944) studied a selected group of war-time head injuries from a military hospital for head injuries, and found an incidence of $2.2 \%$ developing a delayed facial palsy. Potter (1964), however, estimated the incidence of this complication of head injury as about $0.6 \%$. Both authors have cautioned about the difficulty in detecting an immediate facial palsy and which may result in wrong classification as delayed facial palsy. Turner's estimate of this condition would appear to be high for this reason and because of the selected type of cases studied.

We studied these cases in detail clinically and took advantage of electrodiagnostic methods (Puvanendran et al., 1977). Grove (1939), Turner (1944), and Miehlke (1973b) state that $80-90 \%$ of delayed facial palsies make a spontaneous and complete recovery. Our study shows results which are unlike these findings. We have tried to explain the pathogenesis of this condition, and also reviewed other hypotheses on the causation of this palsy.

There is much disagreement about the precise place for surgical exploration of the injured nerve because of lack of knowledge of its natural history and the lack of any method, including electrical

Address for reprint requests: Dr K. Puvanendran, University Department of Medicine (I), Singapore General Hospital, Singapore 3, Republic of Singapore.

Accepted 4 November 1976 studies, for prediction of prognosis at a time when surgical intervention seems most advantageous.

\section{Patients and methods}

During the period May 1974-April 1975, there were $e_{0}^{\mathbb{N}} \mathrm{N}$ 6304 cases of head injury admitted to government㝏 hospitals in Singapore. The chief criterion for admission to hospital was the occurrence of traumatic amnesia or unconsciousness, indicating concussiono 응 of the brain. Knowing that most post-traumatic facial palsies were associated with bleeding earso (Turner, 1944; Briggs and Potter, 1967), all cases of bleeding ear after such closed head injury were studied from the day of head injury to the evolution of the delayed facial palsy in some. Cases of bleeding ear referred for study were those where the bleeding was thought to come from the middle or inner ear. These cases were seen initially daily, and examined clinically and by electrodiagnostic methods. This gave us an accurate indication of the exact time of onset of the facial palsy, and allayed arguments as to whether these were in fact cases of immediate facial palsy which was not obvious because of the obtunded state of the patient immediately after the head injury.

Every case of bleeding ear with facial palsy had radiographs of the skull, including special views to show the petrous temporal bones on both sides. Where no fracture was seen tomograms were prepared.

Cochlear, vestibular, and middle-ear functions were also studied in these cases in detail because of their close anatomical relation to the 7th nerve.

All patients had a detailed neurological examination with special regard to other cranial nerve palsy. The site of the lesion of the facial nerve was 
ascertained by testing the function of its branches, such as lacrimation by the Shirmer test (Miehlke, 1973a), and taste function from the anterior twothirds of the homolateral side of the tongue, in addition to the facial nerve proper. All patients had a complete or partial paralysis of muscles of expression of the whole of one side of the face. The degree of paralysis was estimated visually as a percentage of the normal side (Taverner, 1955). This method was fairly consistent in studying the progress of the palsy, but we often supplemented this with photographs which made comparison easy. By comparison with the opposite side, the weakness was estimated as $25 \%, 50 \%, 75 \%, 100 \%$, using the frontalis, orbicularis oculi, and orbicularis oris muscles, and the average of these estimations was taken. We studied the orbicularis oculi, measuring the palpebral fissure and, on recovery of power, estimating how much more of the eyelash jutted out on attempting tight closure of the eye. We defined as subclinical or latent palsy those cases with abnormal electrical tests but without clinically evident palsy.

All cases were followed up to study the progression of the facial palsy, the recovery, the development of sequelae such as abnormal movement, the cosmetic result, and the patient's satisfaction with the recovery.

\section{Results}

Of the 6304 cases of head injuries admitted to the various hospitals, 39 had bleeding ears. Sixteen of these patients developed delayed facial palsy while three were noted to have an immediate facial palsy at time of injury. Three of these 16 patients had bilateral facial palsies, two of the latter each having a subclinical palsy as defined above. The incidence of bleeding ears in these patients with closed head injuries was $0.6 \%$ and the incidence of delayed facial palsy $0.3 \%$. The chance of a case of bleeding ear developing a delayed facial palsy after head injury was $49 \%$. There was no case of delayed facial palsy who did not have a bleeding ear after head injury, except one patient who had bilateral facial palsy but with bleeding from the right ear only.

There were 12 males and four females with ages 1 anging from 9 to 58 years (Table 1). Eleven patients were involved in traffic accidents while five had fallen. In 14 cases the facial palsy was complete, in three it was partial, while two patients had subclinical palsy. One of the cases of complete facial palsy was partial at first, and it took six days before it became complete.

None of these patients complained of any pain in the appropriate ear apart from pain at the site of impact before the onset of facial palsy. This was looked for especially in cases where facial palsy
Table 1 Delayed facial palsy

\begin{tabular}{|c|c|c|c|c|}
\hline & Males & Females & & Total \\
\hline Side of Palsy & $\begin{array}{l}\text { Right } \\
9\end{array}$ & $\begin{array}{l}\text { Left } \\
10\end{array}$ & $\begin{array}{l}\text { (Bilateral) } \\
\text { (3) }\end{array}$ & $\begin{array}{l}\text { Total } \\
19\end{array}$ \\
\hline Type of Palsy & $\begin{array}{l}\text { Clinical } \\
17\end{array}$ & $\begin{array}{l}\text { Latent } \\
2\end{array}$ & & $\begin{array}{l}\text { Tota } \\
19\end{array}$ \\
\hline Clinical palsy & $\begin{array}{l}\text { Complete } \\
14\end{array}$ & $\begin{array}{l}\text { Partial } \\
3\end{array}$ & & $\begin{array}{l}\text { Tota } \\
17\end{array}$ \\
\hline \multirow[t]{2}{*}{$\begin{array}{l}\text { Site of lesion in } \\
\text { clinical palsy }\end{array}$} & $\begin{array}{l}\text { Geniculate } \\
\text { ganglion }\end{array}$ & $\begin{array}{l}\text { Distal to } \\
\text { chorda } \\
\text { tympani }\end{array}$ & & Tota \\
\hline & 10 & 7 & & 17 \\
\hline
\end{tabular}

developed after a long delay, after the pain of the head injury had disappeared.

SITE OF IMPACT

This was judged from the history and from external injuries. In nine cases the site of impact was around the ear, in two it was over the mastoid bone, and in three over the occipital area. In each of these cases it was on the side of the facial palsy which also corresponded with the side of the bleeding ear. In the three cases who developed bilateral palsy, the site of impact was only over one ear.

\section{SITE OF LESION}

In 10 cases the site of the lesion was found to be at the geniculate ganglion, and in these cases secretion of tears, which is innervated by the greater superficial petrosal nerve, was lost on the side of the lesion, with loss of taste sensation in the anterior two-thirds of that side of the tongue which is innervated by the chorda tympani nerve. In seven cases the taste sensation and lacrymation were intact, and the lesion was considered to be distal to the chorda tympani branch.

\section{ONSET}

The delay in onset of facial palsy after head injury varied from two to 21 days (Fig. 1). In most cases the facial palsy came on between two and seven days. In two instances the onset of delayed facial palsy was indicated by a sudden abnormal prolongation in the terminal latency of facial muscle evoked response, previously shown to be normal in the serial electrodiagnostic tests. In both instances, the subclinical facial palsy occurred 13 to 14 days after the onset of a clinically obvious facial palsy on the opposite side, a delay of 16 to 19 days after head injury. The cases of conduction block had a delayed onset of seven to nine days. In all five cases of complete denervation, who showed the most severe facial palsy, the delay in onset of the facial palsy was between two and six days. The cases of partial denervation had a wider scatter in the day of onset 


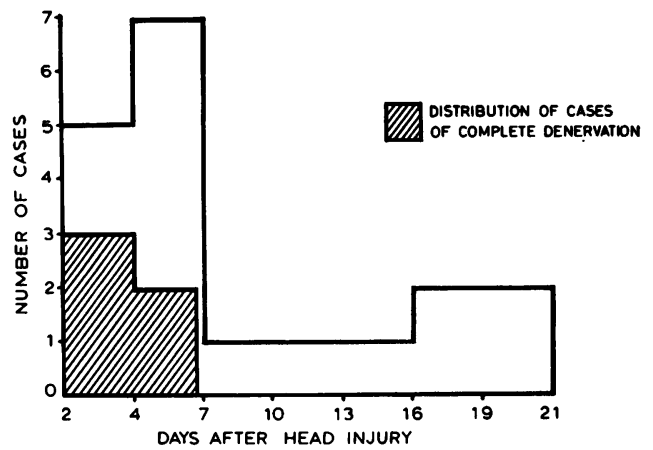

Fig. 1 Delayed facial palsy - day of onset after head injury.

of the palsy, between five and 21 days. In one patient with obvious facial weakness of both sides (Fig. 2a-c), the second facial weakness appeared nine days after the first and was less severe, the first palsy showing complete denervation.

Eight of the 16 patients with delayed facial palsy showed a definite fracture of the petrous bone on the side of the facial palsy (Table 2). Seven cases had a longitudinal fracture while only one was transverse. In two cases with longitudinal fracture the tomogram showed a fracture of the external auditory canal on the side of the facial palsy. In the other eight patients no fracture could be demonstrated despite special petrous radiographs and tomography. This finding contrasted with the three immediate facial palsies where each patient showed a definite petrous bone fracture, two being transverse fractures and one longitudinal.

The 20 cases of ear bleeding without a facial palsy did not show any obvious fracture of the petrous bone. No tomograms were done on these cases.

\section{OUTCOME OF THE FACIAL PARALYSIS}

This could be divided into three patterns depending on the degree of improvement and on the electrical reactions (Table 3): (1) conduction block, (2) complete denervation, and (3) partial denervation. In conduction block, recovery of facial movements was complete and there were no sequelae. In denervation, the facial movements did not recover completely and these patients were left with sequelae. Electrical reactions used to divide these patients into the three groups are described by Puvanendran et al. (1977).

Conduction block occurred in five examples of facial palsy, of which there were three clinical palsies and two subclinical. The other 14 facial palsies developed denervation, six complete and eight partial. Of the three clinical palsies with conduction block, two had only a partial palsy and the other a complete
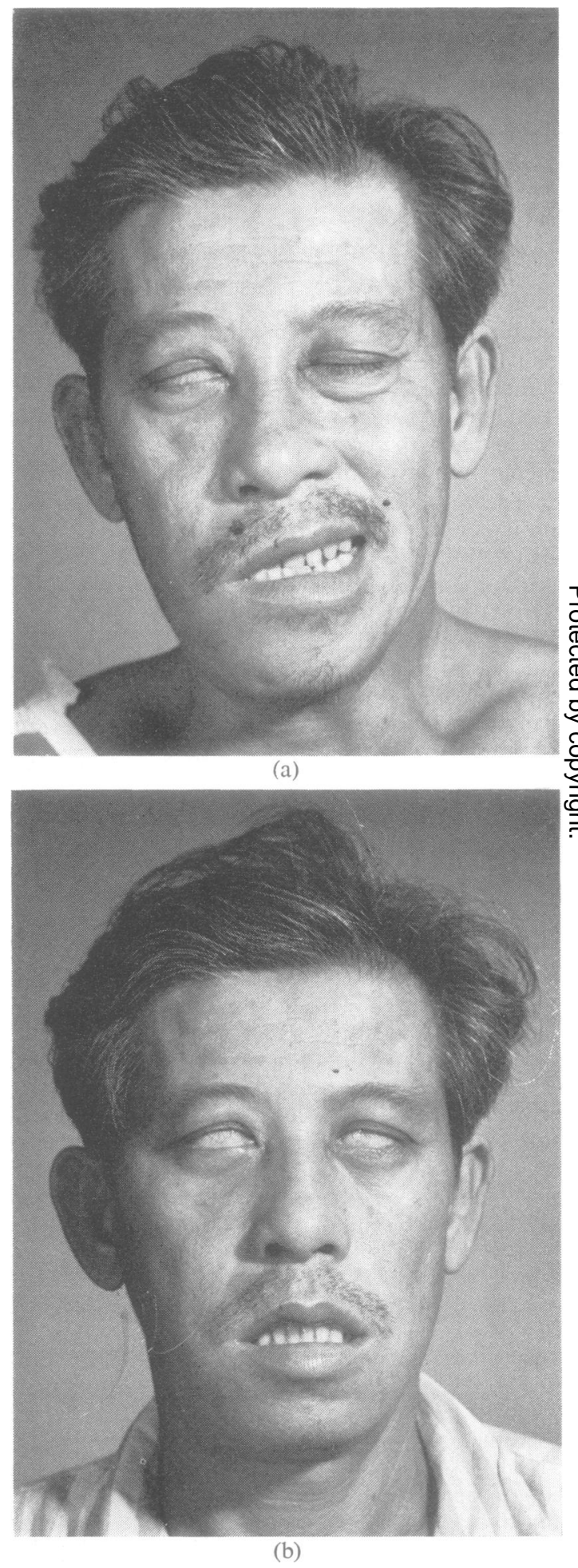


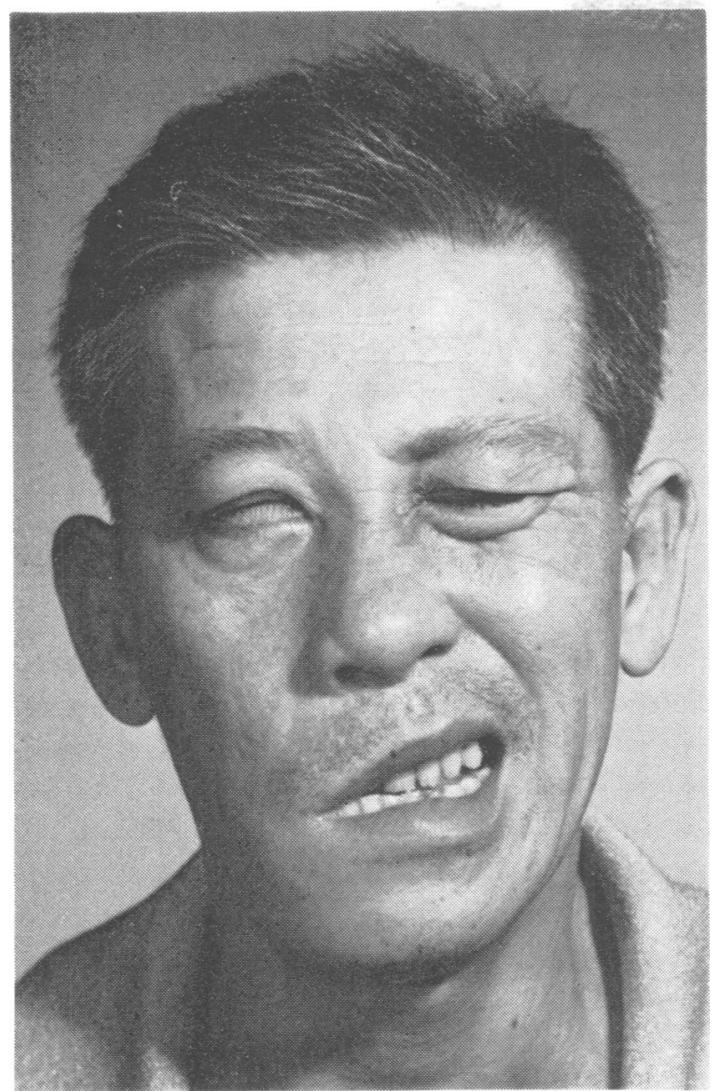

(c)

Fig. 2 Case of bilateral facial palsy after head injury. (a) Right sided facial weakness came on two days after head injury. Left side showed normal power. (b) Left sided weakness came on nine days after right. (c) By the eighth week the left face recovered almost complete power leaving a complete right sided palsy with the mouth pulled to the left side.

Table 2 Delayed facial palsy-petrous fracturebleeding ear

\begin{tabular}{lc}
\hline & $\begin{array}{c}\text { Number of } \\
\text { patients }\end{array}$ \\
\hline Fracture only & 0 \\
Bleeding ear only & 20 \\
Fracture and bleeding ear & 8 \\
Paralysis without bleeding or fracture & 1 \\
Patients with delayed facial palsy & 16 \\
Patients with ear bleeds & 39 \\
Description of petrous fracture & \\
$\quad$ longitudinal & 7 \\
transverse & 1 \\
\hline
\end{tabular}

Table 3 Outcome of delayed facial paralysis-conduction block $17.6 \%$, denervation $82.4 \%$

\begin{tabular}{llllr}
\hline & $\begin{array}{l}\text { Conduction } \\
\text { block }\end{array}$ & $\begin{array}{l}\text { Complete } \\
\text { denervation }\end{array}$ & $\begin{array}{l}\text { Partial } \\
\text { denervation }\end{array}$ & Total \\
\hline & 5 & 6 & 8 & 19 \\
Clinical palsy & 3 & 6 & 8 & 17 \\
Subclinical palsy & 2 & 0 & 0 & 2 \\
Partial palsy & 2 & 0 & 1 & 3 \\
Complete palsy & 1 & 6 & 7 & 14 \\
Site & & & & 7 \\
Distal to chorda & 3 & 1 & 3 & 10 \\
$\quad$ tympani & 5 & 5 & & \\
\hline
\end{tabular}

paralysis, the site of the lesion in all three being distal to the chorda tympani branch. All six facial palsies which developed complete denervation had a complete paralysis clinically, the site of the lesion being at the geniculate ganglion in all except one where the lesion was distal to the chorda tympani branch. In five cases of partial denervation the site of the lesion was at the geniculate ganglion, and in the other three cases it was distal to the chorda tympani branch of the facial nerve. Only one case of the eight with partial denervation electrically showed a partial facial palsy clinically. The seven others showed a complete facial palsy on clinical testing. Thus conduction block occurred in $17.6 \%$ of patients and denervation in $82.4 \%$ of patients.

\section{CLINICAL PROGRESS}

In cases with a conduction block clinical recovery of facial weakness started by about the fifth day (Fig. 3), and was complete by the 36th day (mean). In the two examples of subclinical palsy, the terminal motor latencies of facial muscles returned to normal by the 22nd day and the 56th day after onset respectively.

The mean time for the onset of recovery in partial denervation (assessed electrically) was 13 days and complete recovery occurred by the 95 th day.

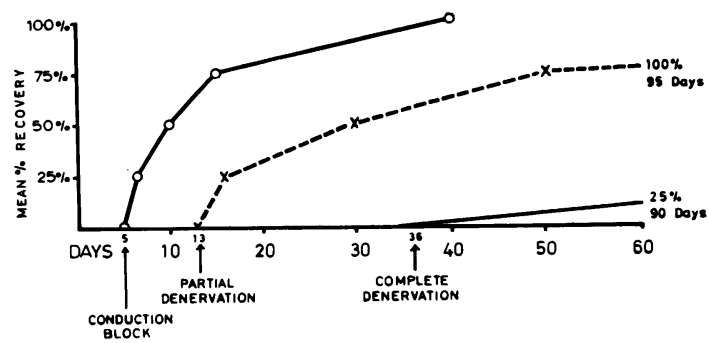

Fig. 3 Clinical progress in delayed facial palsy. 
Where denervation was assessed as complete, clinical recovery began on the 35 th day (mean). By the 90 th day (mean) only a $25 \%$ recovery was seen. None of these cases have so far shown a complete recovery of the facial weakness. Cases 2 and 3 have not shown more than a $75 \%$ recovery by 212 days and 248 days respectively. Case 1 , seen on the 270 th day after injury, has not shown any improvement beyond $25 \%$.

It was easy to detect initial improvement because the first facial muscle to show improvement was the orbicularis oculi muscle, and this is easily estimated by measuring the palpebral gap. It was very constant for recovery to start in that muscle in all cases of complete denervation. It is a long time before the orbicularis oris and frontalis muscles start to show improvement. In most cases with partial denervation recovery starts in the orbicularis oculi but quickly follows in the other facial muscles. In most cases of partial denervation, orbicularis oris was the last muscle to recover whereas after complete denervation the frontalis was the last to recover.

Even though all cases of partial denervation ultimately achieve normal voluntary power of the facial muscles, the spontaneous blink on the side of the palsy remains sluggish for a long time, and may even be permanently slow.

\section{SEQUELAE}

The sequelae of the delayed facial palsy noted were: (1) incomplete return of voluntary movement of facial muscles, (2) asymmetry of the face on repose, and contracture formation; sequelae of abnormal reinnervation following denervation such as (3) associated movements, (4) spontaneous movements, (5) 'crocodile tears'.

All facial nerves showing only a conduction block in our patients recovered completely without any of these sequelae. Even though the six cases of partial denervation recovered full voluntary movement, they were not without the sequelae of abnormal reinnervation. Sequelae in a case of complete denervation (case 1) are shown in Fig. 4, a, b and c.

Contracture of the affected facial muscle often shows as a deepening of the nasolabial fold of that side on repose, and this often improved the facial symmetry on smiling, to the patient's satisfaction. At first glance, the side of the contracture gives the impression of being the normal side and the other as the weak side. Contracture of the orbicularis oculi gives the patient a narrow palpebral fissure which is brought out well on getting the patient to look up. The eyebrow on the side of the palsy may appear to be elevated due to contracture in the ipselateral frontalis muscle.

Due to perversion of reinnervation there may be movement of one part of the face on voluntary movement of another part. A common example is dimpling of the chin or retraction of the angle of the mouth on the side of the palsy when closing the eyes
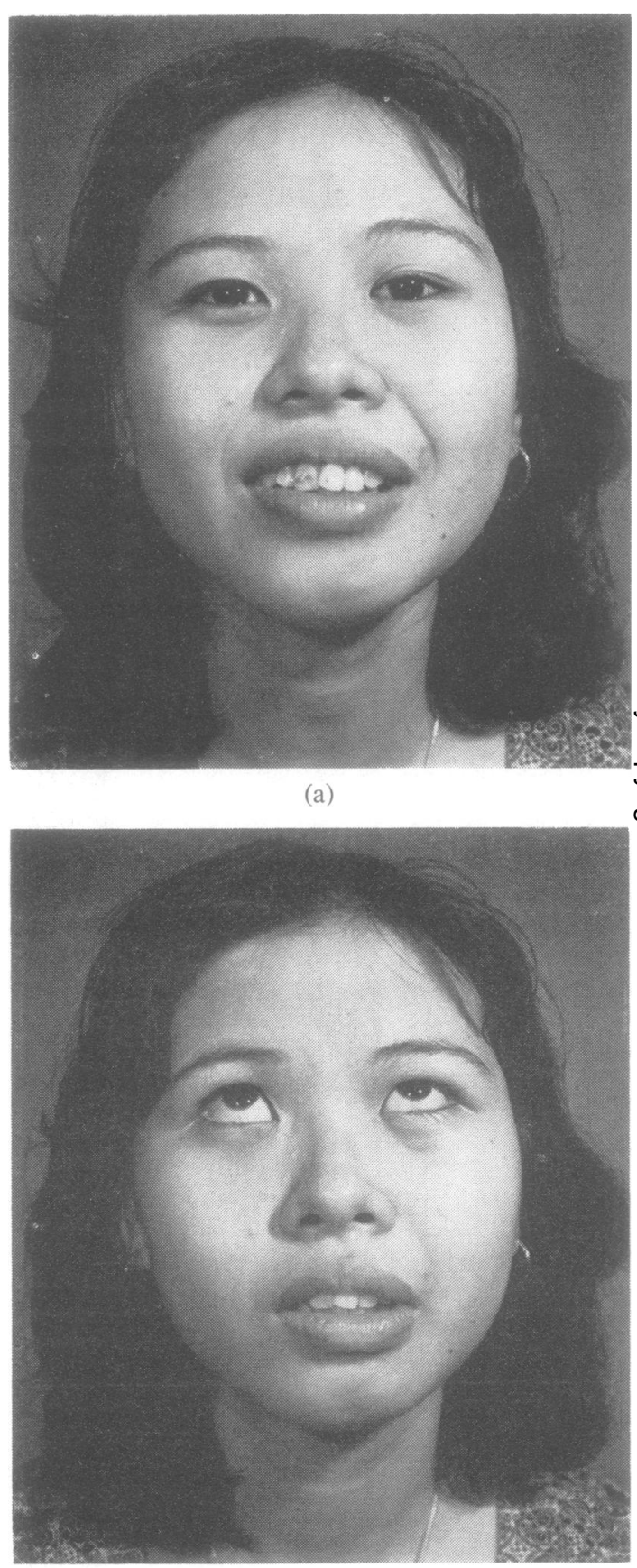

(b) 


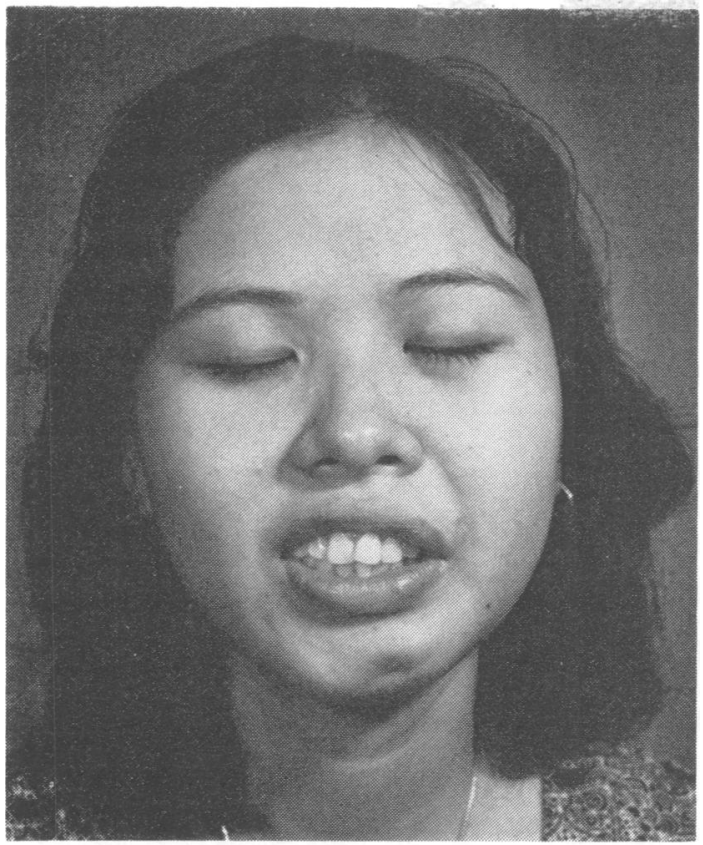

(c)

Fig. 4 Case of left facial palsy after head injury showing the sequelae of complete denervation.

(a) Contracture of left side of face showing as deepening of nasolabial fold on that side on repose. (b) Contracture of orbicularis oculi muscle giving a narrow palpebral fissure on left side. Eyebrow on this side is elevated due to contracture of the frontalis muscle. (c) Dimple on left side of chin and retraction of the angle of the mouth of that side on closing the eye voluntarily or on blinking.

voluntarily. What appears to be a spontaneous twitch of the mouth on the side of the paralysis is in reality associated with involuntary blinking on the side of the palsy, the eye blinking rather sluggishly. This is easily detected on the EMG as bursts of blink potentials when the orbicularis oris muscle is studied. The effort involved in the spontaneous blink is probably channelled between this movement and the mouth, resulting in a drag on that eyelid.

The crocodile tear phenomenon is seen as unilateral lacrimation on eating. In one of our patients unilateral lacrimation was also observed on smiling, on reading, and during facial nerve stimulation.

None of the patients with a conduction block of the facial nerve developed a contracture. The longest time that any of these cases took to recover completely was $\mathbf{4 0}$ days. The earliest day any of the cases studied was noted to have a contracture was 58 days. The cases with a conduction block improved fully, well before the minimum time required for development of contracture in this series, and this possibly explains why these patients were spared from contractures. Only six of the 14 cases of denervation had obvious contracture. The case with a bilateral facial paralysis maintained a symmetrical mouth until about the eighth week when the left face recovered almost complete power, the mouth became pulled to the left side, and the right face was still completely paralysed (Fig. 2).

While no case with a conduction block developed abnormal movement, all cases with denervation except one developed some form of abnormal movement. One case developed crocodile tears after the 30th week, and it is interesting to note that in this patient the lesion in the facial nerve was at the level of the geniculate ganglion as indicated by loss of tear secretion and taste sensation in the anterior two-thirds of the tongue on that side at the onset. This patient, who used to have tears pouring down her cheek, showed some improvement possibly with returning tone in the orbicularis oculi which increases the efficiency of the lacrimal duct in draining all that outpouring of tears.

All cases, except the five palsies with conduction block and one patient with a partial denervation, had some sequelae which disfigured the face. Most of these, especially the abnormal movement, could be permanent.

Hearing loss Four patients were left with normal audiometry while 10 had a perceptive or mixed deafness (Tables 4,5 ). None had a pure conduction deafness.

Vestibular function Seven patients had abnormal vestibular function on the side of the facial palsy.

The only other cranial nerve palsy observed in these 16 cases was a 6th nerve palsy of the opposite side in one patient. There was no instance of olfactory

Table 4 Audiometry

\begin{tabular}{lll}
\hline & $\begin{array}{l}\text { Side of facial } \\
\text { palsy only }\end{array}$ & Bilateral \\
\hline Mixed deafness & 1 & 3 \\
Perceptive deafness & 4 & 2 \\
Pure conduction deafness & 0 & 0 \\
Normal & 0 & 4 \\
\hline
\end{tabular}

Table 5 Hearing loss

\begin{tabular}{llll}
\hline & $30-40 \mathrm{db}$ & $40-60 \mathrm{db}$ & $>60 \mathrm{db}$ \\
\hline $\begin{array}{l}\text { Side of facial injury } \\
\text { Mixed deafness }\end{array}$ & 1 & 3 & 0 \\
$\begin{array}{l}\text { Perceptive deafness } \\
\text { Opposite side }\end{array}$ & 0 & 2 & 3 \\
$\begin{array}{l}\text { Mixed deafness } \\
\text { Perceptive deafness }\end{array}$ & 1 & 1 & 0 \\
& 0 & 1 & 0 \\
\hline
\end{tabular}


nerve involvement. One patient had an associated subdural haematoma which was evacuated. None of these patients had evidence of diabetes mellitus or hypertension.

\section{Discussion}

In facial palsy after closed head injury, a fracture of the base of the skull is usually assumed to be present. In our cases, all those who had a fracture of the petrous bone and bleeding ear developed a facial palsy. This finding contrasts with that of Potter (1964) who says that there is a $50 \%$ chance of having some facial weakness, and a $38.5 \%$ chance of a delayed facial weakness if there is both a fracture and a bleeding ear (Briggs and Potter, 1967).

Petrous bone fractures that cause facial paralysis are either transverse or longitudinal. Transverse fractures are uncommon and account for only $10 \%$ of temporal bone fracture (Tos, 1971). Transverse fracture rarely causes bleeding from the ear or fractures of external auditory canal. Facial nerve palsy occurs in $30-50 \%$ of transverse fractures, and the paralysis is likely to be immediate in onset and complete because of nerve disruption (McHugh, 1959; Harker and McCabe, 1974; Miehlke, 1973b).

Up to $90 \%$ of all petrous fractures are longitudinal. Unlike the former type, longitudinal fracture very often passes through the external auditory canal, and usually tears the tympanic membrane producing bleeding from the external auditory canal. Facial paralysis occurs in 10-25\% of these cases (McHugh, 1959; Kettel, 1958; Harker and McCabe, 1974), and the onset of paralysis is usually delayed (Ulrich, 1926).

In our cases, $50 \%$ of delayed facial palsies had a fracture of the petrous bone, $12 \%$ transverse and $88 \%$ longitudinal. This contrasted with the three cases of immediate facial palsy where all had demonstrable petrous fracture, transverse in two and longitudinal in one. This leads us to doubt the assumption of earlier authors that in facial palsy after closed head injury, a fracture of base of skull may be assumed. It leads also to the question as to what causes the delayed facial palsy in these cases.

In the facial canal, the area occupied by the facial nerve is only $30-50 \%$ (at its greatest width) of the cross-sectional area of the canal. The remainder of the facial canal is occupied by blood vessels with connective tissue loosely arranged around it (Sunderland and Cosser, 1953). In immediate facial palsy it is easily assumed that the fracture damages or causes severance of the facial nerve. Delayed facial palsy is possibly the result of bleeding into the facial canal. Increasing size of a haematoma in the limited non-expanding bony tube could press on the facial nerve, and ultimately cut off its blood supply, causing ischaemic damage to the nerve. If the pressure were mild, there would be only a neuropraxia or conduction block due to segmental demyelination. If the damage were more severe, there could be axonal damage with denervation.

As half of our patients with delayed facial palsy did not show a petrous fracture on special radiological views and tomograms, it may be possible to have bleeding into the facial canal from the blood vessels found loosely supported around it, somewhat akin to a subdural haemorrhage due to a sudden shearing force (Kettel, 1958). The bleeding from the ear comes from the middle or internal ear, and it is coincidental in this injury.

Briggs and Potter $(1967,1971)$ postulate a similar mechanism for this facial weakness as in Bell's palsy with a possible inflammatory reaction in and around the nerve, or a swelling of the nerve in the canal which could lead to ischaemia. On this postulate, they claim that prophylatic injection of ACTH after head injury can reduce the incidence of delayed palsy. Jongkees (1972) thinks that the nerve could be compressed by its swelling within its fibrous sheath or epineurium, and this swelling may be a delayed response to trauma to the nerve itself, or secondary to damage to its surrounding vasculature resulting in delayed arterial spasm or arterial or venous thrombosis. Turner (1944) says that external pressure on the nerve by blood in the Fallopian aqueduct is the likely cause of delayed facial palsy. Robson and Dawes (1960) attribute this palsy to pressure on the facial nerve from oedema of the mucosa of the facial canal which was non-bacterial and was a reaction to the presence of blood. However, this would not explain an onset of facial palsy as early as one hour after head injury in one of his cases. Such rapid onset could only be explained by rapid bleeding into the facial canal.

We note many dissimilarities between delayed facial palsy and Bell's palsy, and hence assume a difference in their mechanisms. Unlike Bell's palsy, the upper limit of the lesion extended very often to the geniculate ganglion in $59 \%$ of cases, and ear pain at onset was not seen. The outcome of the facial palsy was much worse than in Bell's palsy. Only $17.6 \%$ of our patients had a conduction block and $82.4 \%$ had denervation, whereas more than $60 \%$ of cases of Bell's palsy show a conduction block (Taverner, 1959; Groves, 1973; Kristensen, 1968), and thus a better chance for complete recovery without abnormal reinnervation. Miehlke (1973a, b) gives his impression that $90 \%$ of cases of late traumatic facial paralysis resolve, regaining satisfactory nerve function without surgical intervention. This figure, however, is a clinical impression not 
supported by electrical studies. He does not mention how much of nerve function recovery and sequelae is acceptable. The duration of weakness was more protracted with delayed facial palsy showing either denervation or conduction block when compared to Bell's palsy (Taverner, 1959).

The electrical reaction after complete traumatic denervation is different from that after Bell's palsy with complete denervation: the conduction time increased before excitability finally disappeared. There were also differences in electrical reaction between these disorders in partial denervation and conduction block.

We have discussed in detail the natural history, including the rates of clinical recovery, and the sequelae including those from abnormal reinnervation. Lipschitz (1906) explained these phenomena as a misdirection of a branch of the regenerating axon into an axon sheath leading to a different part of the face. This theory is supported by experimental studies by Howe et al. (1937) in the monkey.

A possibility of complete denervation arises if the facial palsy comes on two to six days after head injury. Complete facial palsy often ends up with denervation. In our cases, a lesion that extended up to the geniculate ganglion was always associated with denervation. In bilateral palsy, the second one was milder if its onset was more delayed, and with longer delay it could manifest as a latent palsy. Electrodiagnostic methods were most useful in indicating prognosis very early in the disease. An interesting phenomenon noted was a neuropraxic involvement of the 'uninvolved' side of face in two patients. Almost all cases with denervation have shown abnormal facial movement.

In view of the poor outcome in our series when left to its natural course, we believe that decompression of the facial nerve in the facial canal should be considered at the earliest indication of denervation (Jongkees, 1965). As the facial nerve lesion often extends up to the geniculate ganglion, the entire facial nerve in the temporal bone should be decompressed, and this would involve a combined translabyrinthine and middle cranial fossa approach (Miehkle, 1973b). If the geniculate ganglion is intact, a mastoid approach would be adequate.

We wish to thank Mr E. H. Goh, Head of the ENT Department, Singapore General Hospital for allowing us to study patients under his care.

\section{References}

Briggs, M. and Potter, J. M. (1967). Prevention of delayed traumatic facial palsy. British Medical Journal, 4, $464-465$.
Briggs, M. and Potter, J. M. (1971). Prevention of delayed traumatic facial palsy. British Medical Journal, 3, 458-459.

Grove, W. E. (1939). Skull fracture involving the ear: a clinical study of 211 cases. Laryngoscope (St. Louis), 49, 678-833.

Groves, J. (1973). Facial palsies: Selection of cases for treatment. Proceedings of the Royal Society of Medicine, 66, 545-549.

Harker, L. A. and McCabe, B. F. (1974). Temporal bone fractures and facial nerve injury. Otolaryngologic Clinics of North America, 7, 425-431.

Howe, H. A., Tower, S. S., and Duel, A. B. (1937). Facial tic in relation to injury of the facial nerve. Archives of Neurology and Psychiatry (Chicago), 38, 1190-1198.

Jongkees, L. B. W. (1965). Facial paralysis complicating skull trauma. Archives of Otolaryngology, 81, 518-522.

Jongkees, L. B. W. (1972). On peripheral facial paralysis. Archives of Otolaryngology, 95, 317-323.

Kettel, K. (1958). Peripheral Facial Palsy. Pathology and Surgery, p. 246. Blackwell Scientific Publications: Oxford.

Kristensen, H. F. (1968). Discussion on facial paralysis. Journal of Laryngology and Otology, 82, 665-666.

Lipschitz, R. (1906). Beiträge zur lehre von facialislähmung nebst Bemerkungen zur trage der nervenregeneration. Monatsschrift für Psychiatrie und Neurologie (Basel), 20, 84.

McHugh, H. E. (1959). Surgical treatment of facial paralysis and traumatic conductive deafness in fractures of temporal bone. Annals of Otology, Rhinology and Laryngology, 68, 855-889.

Miehlke, A. (1973a). Surgery of the Facial Nerve, 2nd edition. Urban and Schwarzenberg: Munich.

Miehlke, A. (1973b). Recognition and management of facial nerve palsies of operative and traumatic origin. Proceedings of the Royal Society of Medicine, 66, 549-554.

Potter, J. M. (1964). Facial palsy following head injury. Journal of Laryngology, 78, 645-657.

Potter, J. M. and Braakman, R. (1976). In Handbook of Clinical Neurology. Edited by P. J. Vinken and G. W. Bruyn, Vol. 24, 105-117. North-Holland Publishing Company: Amsterdam, Oxford.

Puvanendran, K., Vitharana, M., and Wong, P. K. (1977). Electrodiagnostic study in delayed facial palsy after closed head injury. Journal of Neurology, Neurosurgery, and Psychiatry, 40, 351-357.

Robson, F. C. and Dawes, J. D. K. (1960). Delayed facial paralysis of lower motor neurone type following head injury. Journal of Laryngology and Otology, 74, 275-289.

Sunderland, S. and Cosser, D. F. (1953). The structure of the facial nerve. Anatomical Record, 116, 157-162.

Taverner, D. (1955). Bell's palsy, a clinical and electromyographic study. Brain, 78, 209-228.

Taverner, D. (1959). The prognosis and treatment of spontaneous facial palsy. Proceedings of the Royal Society of Medicine, 52, 33-39.

Tos, M. (1971). Fractura ossis temporalis. Forløbet og følger of 248 petrosafrakturer. Ugesker Laeger, 13, 1149-1156. 
Turner, J. W. A. (1943). Indirect injuries of the optic nerve. Brain, 66, 140-151.

Turner, J. W. A. (1944). Facial palsy in closed head injuries. Lancet, 246, 756-757.
Ulrich, R. (1926). Verletzung des Gehörorgans bei Schädelbasisfrakturen. Acta Oto-Laryngologica (Stockholm), Suppl. 6, 1. 